\title{
Contrastive error analysis of Turkish EFL learners in writing
}

\author{
Şahin GÖK \\ Department of Foreign Language, Istanbul Gelisim University
}

DOI: http://doi.org/10.36892/ijlls.v2i2.429

\begin{tabular}{|c|c|}
\hline & $\begin{array}{l}\text { Abstract } \\
\text { The aim of this study is to find out to what extent Turkish EFL stud }\end{array}$ \\
\hline & $\begin{array}{l}\text { interlingual (interference) and intralingual (developmental) errors in writing } \\
\text { at the university level. The mid-term and final examination papers of } 50 \\
\text { Turkish EFL students were taken and their errors were categorized into }\end{array}$ \\
\hline $\begin{array}{l}\text { Keywords: } \\
\text { contrastive analysis, } \\
\text { error analysis, } \\
\text { developmental } \\
\text { errors, interference } \\
\text { errors }\end{array}$ & $\begin{array}{l}\text { interference and developmental errors. The results of our research have } \\
\text { shown that they made a mean of \% } 14.6 \text { interference errors. Thus, this } \\
\text { proportion does not confirm the contrastive analysis hypothesis claiming that } \\
\text { all errors are due to the negative transfer from the mother tongue. On the } \\
\text { other hand, they made a mean of \% } 85.4 \text { developmental errors which are not } \\
\text { related to L1. So the results of T-Test indicate that Turkish EFL students made } \\
\text { significantly more }(p<.001) \text { developmental errors. }\end{array}$ \\
\hline
\end{tabular}

\section{INTRODUCTION}

During 1950's behavioristic psychology and structural linguistics were dominant in language learning and teaching. Behaviorists viewed errors as bad habits or interference from the mother tongue (Klassen, 1991). Thus, EFL teachers and researchers gave much importance to the widely accepted contrastive analysis hypothesis. They claimed that the principal obstruction to the second language acquisition was the "interference of the first language system with the second language system" (Brown 1980, p. 148). Corder (1967) explains the source of errors as "influence of the mother tongue in the learning process, interference... from the habits of the first language" (p. 161).

But learners have been making errors while learning a second language. Many of the learners' errors have shown no relation to the features of their mother tongue. So an alternative view of analyzing errors was found. In 1960's a major change was seen in the second language acquisition theories. The shift from behaviorism to cognitivism has affected the attitude of both researchers and teachers toward errors that learners make in the foreign language (Walz, 1982). This has also led to a change in the approach of analyzing errors.

During the late 1960's, in transformational-generative grammar, in first language acquisition research, and especially in cognitive psychology, there was a shift from behaviorism toward making language teaching more humanistic and less mechanistic (Unal, 1989). Also second language acquisition (SLA) was associated more with first language (L1) acquisition. Just as children make many errors during the learning period without breaking down in their communication, adults can also learn a new language by a trial-and-error approach (Walz, 1982). Therefore, errors are seen as the indicators of learning which is taking place and that the Language Acquisition Device (LAD) is working. Klassen (1991) states that errors are no longer "bad" but "good" (p.10), because in the cognitive approach errors are seen as a natural part of learning and teaching (Edge, 1989). So the notion of language learning has changed "from preventing errors to learning from errors" (Unal 1989, p.94).

So the teacher can get benefit from error analysis to find out the problems and difficulties of learners. The teacher can therefore build up a profile of each student's problems and see to what extent his grasp of the target language is improving. By using "an error analysis as a monitoring 
device, the teacher can assess more objectively how his teaching is helping his students" (Norrish, 1983, p. 80).

Since the first language interferes with the second language acquisition, Turkish EFL learners seem to make negative transfer from Turkish into English. However, some of the errors are not due to the interference of the mother tongue and they are called developmental or intralingual errors. The main focus of this research will therefore be on interference and developmental errors.

\subsection{Theory and Attitudes towards Errors}

In the years between 1950 and 1960 there were two principal schools of thought in the field of ESL/EFL methodology with respect to the learner errors (Richards, 1974). The focus of the first school was on grammatical accuracy, that is, learner errors were a sign of failure. Contrary to the first view, the second school claims that "we live in an imperfect world and consequently errors will always occur in spite of the teachers' best efforts" (Richards, $1974 \mathrm{p}$. 20). The two distinct views are represented in the behaviorist and cognitive approaches to language learning.

\subsection{Identification of Errors}

The first step in the process of error analysis is to define "errors" as precisely as possible. A distinction has been made in the literature between "competence errors" and "performance errors". This has led to a distinction between "errors" and "mistakes" (Lott, 1983).

Janicki (1985) defines mistakes as related to the performance of the learner whereas errors are due to his/her insufficient knowledge of the rules of the language, i.e. competence. Mistakes are called lapses because they are not systematic and may be corrected by language users when they notice them. Errors are systematic and they indicate that the learner has not mastered the structure of the target language. Edge (1989) describes learner errors by saying that besides slips or lapses "we must have a category of mistakes which individual learners couldn't correct even if they are warned about it" (p. 9). Consequently, both language learners and native speakers make mistakes which are correctable without the help of the teacher or the listener.

\subsection{Analyzing Errors}

There has been a growing interest in analysis of errors learners make while performing a second language. According to behaviorists errors are "bad habits" and should be corrected immediately. On the contrary, the cognitivists see errors as a natural part of the learning and tolerate them unless they break down communication (Norrish 1983). In the following sections two approaches, Contrastive Analysis (CA) and Error Analysis (EA), are discussed.

\subsubsection{Contrastive Analysis}

As indicated in the second section of this chapter, during the 1950s and 1960s the field of first language acquisition was dominated by behaviorist ideas. In the behaviorist approach error treatment in language learning rested on a comparison of the learner's native and target language. Since the second language learner already possesses a set of habits from his native language, some of these habits will help the new learning task while others will hinder it (Littlewood, 1984).

According to the contrastive analysis approach, the linguistic system of the mother tongue of the learner (L1) resembles that of his target language (L2) and the learner therefore learns the similar features in L2 by transferring them from L1 into L2. If the transfer helps the learning it is called positive transfer. But sometimes L1 and L2 may differ in phonology, syntax and lexicon. This difference between the two hinders language learning and thus it is called interference or negative transfer (Littlewood, 1984). In CA it is assumed that interference of the mother tongue is responsible for the errors made during the transitional period of learning the target language (Klassen, 1991). Robinnet and Schachter (1983) claim that a careful comparison of the native language of the learner with the target language will result in predictable problems 
for the learner. Thus, it is maintained that the contrastive analysis helps the learner by predicting those problems. Finocchiaro (1974) believes that students understand the reasons for their errors and avoid committing them when they are aware of the contrasts between L1 and L2.

There are two versions of the contrastive analysis: a strong version and a weak version. Lado (1957) explains the strong version as follows:

The plan of the book rests on the assumption that we can predict and describe the patterns that will cause difficulty in learning, and those that will not cause difficulty, by comparing systematically the language and culture to be learned with the native language and culture of the student. (p. vii)

Wardhaugh (1970) argues that:

The weak version requires of the linguist only that he uses the best linguistic knowledge available to him in order to account for observed difficulties in the second language learning. It does not require ... the prediction of those difficulties. It starts with the evidence provided by linguistic interference and uses such evidence to explain the similarities and differences between systems (pp. 123-130)

The strong version of CA has been criticized and found unrealistic and impractical. But on the other hand the weak version has certain possibilities to be used. However, even the weak version is subject to the extensive debate (Wardhaugh, 1970).

Since error treatment through contrastive analysis could not account for the causes of all errors in language learning, researchers began to investigate other sources of errors and their attempts have given way to another approach-Error Analysis.

\subsubsection{Error Analysis}

A great deal of empirical research has been done on errors of foreign language learners in search of their cause. Research has indicated that many errors made by learners would not have been predicted by contrastive analysis. And this suggests that interference from the mother tongue is not the only source of error (Littlewood, 1984).

Dulay \& Burt (1974) have challenged the role of interference and habit formation in second language learning. In their study they recorded the English speech of 145 children and found that only $3 \%$ of the children's errors could be classified as interference errors. On the other hand, they classified 85 per cent as developmental errors.

Another researcher Grauberg (1971) found, in his analysis of English errors of German native speakers in an essay writing task, that mother tongue interference could account for only 25 per cent of the lexical errors, 10 per cent of the syntactic errors and none of the morphological errors.

Error analysis (EA) has become distinguished from contrastive analysis in that it examines all possible sources of errors, not just those which result from negative transfer of the mother tongue. EA has brought to the attention of the EFL/ESL teachers and researchers the multiple origins of learners' errors (Unal, 1989). Thus, researchers and teachers of second and foreign languages here realized that mistakes of the learner made in the process of constructing a new system of language should be analyzed carefully, for they possibly reveal the keys to understanding the process of second language acquisition (Dulay, Burt \& Kashan, 1982). Littlewood (1984) notes that errors of language learners are no longer signs of failure in learning but they are useful for both teachers and students because they offer hints about the learning strategies and mechanisms which learners employ. Likewise, Gass and Selinker (2008) also note that errors are viewed as clues of a learner's attempt to figure out language system to force regularity on the language he or she is exposed to.

In speaking about the benefits of error analysis, Sharma (1981) says:

Error analysis is a process-based approach on analysis of learners' errors with one 
clear objective: evolving a suitable and effective teaching-learning strategy and remedial measures necessary in certain clearly marked out areas of the foreign language ... it can reveal to the teacher, the course designer, or the textbook writer the "knotty" areas of language confronting the pupils (p.76)

In EA, errors are identified and classified into types, then their source and degree of disturbance are determined. Errors arise from several possible general sources: interlingual errors, the sociolinguistic context of communication, psycholinguistic or cognitive strategies (Unal, 1989). In the following section errors of EFL learners will be identified and classified.

\subsubsection{Development Errors}

Developmental errors are those which the learner makes in the target language just as in his/her mother tongue. When the learner attempts to use L2 with his limited knowledge of the rules of that language s/he commits these types of errors which are not due to interference from his L1. When these types of errors are made by a learner, it seems to reflect that mental mechanisms underlying general language development come into play (Dulay, et al, 1982). And Richards (1983) reports that "developmental errors reflect the strategies by which the learner acquires the language... and that the learner is making false hypotheses about the target language based on limited exposure to it" (p. 274).

\subsubsection{Inferences Errors}

Interference errors are similar in structure to semantically equivalent phrases or sentences in the student's native language. They were mentioned earlier in this chapter as negative transfer from the learner's mother tongue. Researchers usually identify interference errors by comparing the structure of the learner's error in L2 to that in L1. If there is a similarity between the two language structures, they are called interference error (Dulay, et al, 1982). For example, when a Turkish EFL learner utters a sentence like I am knowing it, the "-ing" tense marker is transferred from his own native language because the verb know (bilmek) is usually used in the continuous form in Turkish.

Lado (1957) finds differences between German and English and says:

..English uses the function word $d o$, does, did before the subject to achieve the word order signal of that type of question. German does not use that device. We may expect a German speaker to say, for example, *Know you were the church $i s$ ? as a question instead of Do you know where the church is? He will simply be transferring the German pattern Wissen Sie wo die Kirche ist? which is similar to the pattern used with the verb be in English but not with the verb know (p 15).

Lott (1983) did a contrastive analysis research between Italian and English and found out some interference and developmental errors between the two systems:

a) English process is used in the meaning of trial because the Italian word processo means trial. Because of the phonetic similarity, the student mixes them.

b) English work is used to mean job as in the sentence I have a good work because of the semantic feature of it. In Italian the word lavoro is used for both for work and job.

c) Since some grammatical distinction does exist in the native language (Italian) Lott (1983) found students had difficulty with the present perfect (I have gone) different from the simple past (I went) because both forms are in most contexts interchangeable in Italian.

d) As makeldo distinction does not exist in Italian; the students misuse them. For example, a student wrote: The company makes business in India (p. 259).

Like Lott, Mukattash (1986) reports about L1 interference as follows:

Although some recent studies indicate that the number of L1 induced errors is rather insignificant on the syntactic level, the present study demonstrates that a large number of the grammatical errors made by the subjects are in fact the result of interference from Arabic. (p. 200) 


\section{METHOD}

\section{The Purpose of This Study}

Our aim for doing this research is to find out to what extent Turkish EFL students make interference and developmental errors in writing. We hope that the result of this research will help Turkish EFL teachers in teaching those problematic items.

\subsection{Subject}

The subjects of this study are 50 Turkish EFL students in the first class of the Department of English Language and Literature. They take writing course after an English preparation program.

\subsection{Tools}

T-Test computation was used to measure the relationship between the number of the interference and developmental errors and the figures were illustrated in the tables.

\subsection{Data Collections}

Turkish EFL Students' 50 composition papers were taken, and their errors were categorized into two types: interference and developmental errors. They are the old mid-term and final composition examination papers.

\section{ANALYSIS AND THE RESULTS}

This study is both a quantitative and descriptive examination to explore to what extent Turkish EFL students make interference as opposed to developmental errors in writing. To measure the difference between the number of the interference and developmental errors, a TTest was used.

Table 3.1 presents the descriptive data of EFL students' developmental and interference errors. Table 3.2 shows the means and standard deviations of the developmental and interference errors made by Turkish EFL students while Table 3.3 represents the results of T-Test of those errors.

The results in Table 3.1 shows that $\% 85.4$ of the students' errors are developmental errors which are not related to the first language and that only $\% 14.6$ of their errors are interference errors which are due to the negative effect of the mother tongue. This result confirms Dulay \& Burt's (1974) study. In their study they recorded the English speech of 145 children and found that only $3 \%$ of the children's errors could be classified as interference errors. On the other hand, they classified 85 per cent as developmental errors. Also, the result of a study by Elkıliç (2012) shows similar results stating that 890 (\%88) errors of Turkish students out of 1011 are general errors, only $121(\% 12)$ of them are interference errors.

Table 3.1

Total Number of Errors

\begin{tabular}{|c|c|c|}
\hline $\begin{array}{c}\text { Developmental } \\
\text { Errors }\end{array}$ & $\begin{array}{c}\text { Interference } \\
\text { Errors }\end{array}$ & TOTAL \\
\hline $264(\% 85.4)$ & $45(\% 14.6)$ & 309 \\
\hline
\end{tabular}

Table 3.2

Mean and Standard Deviation of EFL Students' Errors

\begin{tabular}{|c|c|}
\hline Developmental Errors & Interference Errors \\
\hline Total: 264 & Total: 45 \\
\hline Mean: 5.28 & Mean: 0.9 \\
\hline SD: 2.99 & SD: 1.44 \\
\hline
\end{tabular}


A T-Test was used to analyze the relationship between the number of the developmental and interference errors of EFL students. The result of the T-test is as follows: Tobs $=4.56$

Table 3.3

Descriptive Statistics for Errors Made by EFL Students

\begin{tabular}{|c|c|c|c|c|}
\hline & $\begin{array}{c}\text { Developmental } \\
\text { Errors }\end{array}$ & $\begin{array}{c}\text { Interference } \\
\text { Errors }\end{array}$ & $\begin{array}{c}\text { Mean } \\
\text { Difference }\end{array}$ & Tobs. \\
\hline M & 5.28 & 0.9 & 4.38 & \multirow{2}{*}{4.56} \\
\hline SD & 2.99 & 1.44 & ------ & \multirow{2}{*}{ T } \\
\hline
\end{tabular}

The results of T-Test as shown in Tables 3.3 indicate that EFL students made significantly more $(\mathrm{p}<.001)$ developmental errors than interference errors $($ Tobs $=4.56, \mathrm{df}=49)$. For example, students made a mean of 85.4 developmental errors but on the other hand they made only a mean of 14.6 interference errors in writing. Therefore, the results of our study support the use of error analysis rather than contrastive analysis because most of the errors (\%85.4) are developmental errors not interference from the mother tongue.

\section{Descriptive analysis}

In this section of the study certain interference and developmental errors, collected from the students' papers, will be investigated. We can classify them as follows:

a) students just translate idioms or expressions from Turkish into English word by word. For instance, a student wrote: Fatih Sultan Mehmet from the greats, the Turkish meaning of this expression is Büyüklerden Fatih Sultan Mehmet. Another student wrote: Alcoholism is the mother of the all bad habits the Turkish translation of which is İçki bütün kötülüklerin anasıdır. He has just translated the expression word by word. They also use visa instead of midterm examination.

b) We also observed that learners omit and add certain prepositions. For example, in the following sentence for was omitted, I am waiting you because in Turkish there is no preposition in the same sentence. It means Seni bekliyorum.

Another student wrote: My family is affected from my bad luck..., in this sentence s/he misused the preposition from since in Turkish we use "Ailem benim kötü şansimdan etkilenir", here dan means from.

Another example shows that Turkish students often confuse the use of from because of the negative transfer from L1. A student wrote: Are we responsible from this..., we use in Turkish; Bundan biz mi sorumlu muyuz..., here dan means from.

We also observed the omission of certain prepositions such as "to" in the sentence: at that time others listen music, because Turkish language has no preposition with the word listen, we use it as, o zamanda diğerleri müzik dinler.

c) Learners misused the preposition in as in the sentence: They have a friend who lives in abroad, the meaning of the underlined phrase in Turkish is yurt dişında, here $d a$ means in.

d) Learners misused some verbs in English because of the negative effect of Turkish, for instance a student wrote: I won the university entrance exam, which means in Turkish: üniversite giriş sinavinı kazandım, in this sentence to win means kazanmak which is used as to pass an exam in Turkish. Another student wrote: I went to the army; it is the mere word by word translation of Turkish usage into English. We say in Turkish Ben (I) asker (the army) $e$ (to) gittim (went). The meaning of the utterance is: to join the army or to do military service.

e) Learners confused in using the present simple and the simple past in storytelling. One of the students begins his story as in the following:

"Spaceship moves silently in space. It is coming from the depth of universe. 
Reconnaissance of military is concluded pretty good. It landed on the base for report. Captain Thomas reports to the commander the circumstance of moon base..."

\section{CONCLUSION}

As we hypothesized that Turkish EFL students make interference errors in learning English the results of our research have shown that they made a mean of \%14.6 interference errors. But this proportion does not confirm the contrastive analysis hypothesis claiming that all errors are due to the negative transfer from the mother tongue. On the other hand, they made a mean of \%85.4 developmental errors which are not related to L1. So the results of T-Test as shown in Tables 3.3 indicate that EFL students made significantly more $(\mathrm{p}<.001)$ developmental errors than interference errors $($ Tobs $=4.56, \mathrm{df}=49)$. And this result therefore confirms the result of the study done by Dulay \& Burt's (1974).

The result of the present study also confirms the result of the study of another researcher Grauberg (1971). He found, in his analysis of English errors of German native speakers in an essay writing task, that mother tongue interference could account for only 25 per cent of the lexical errors, 10 per cent of the syntactic errors and none of the morphological errors. A similar study by Elk1liç (2012) also confirms our study and states that intermediate level students committed a total of 1011 errors, whereas 890 (\%88) of the errors are general errors, only 121 (\%12) of them are interference errors.

\section{Pedagogical implication}

As a result, this study has revealed that Turkish EFL students made only a mean of $\% 14.6$ interference errors and a mean of \%85.4 developmental errors. And this result confirms the results of the studies done by Dulay \& Burt (1974) and Grauberg (1971) and Elkıliç (2012). Students also made certain errors which can be classified into: a) translation of idioms or expressions from Turkish into English without considering the target language culture and system, b) omission and addition of certain propositions, c) misusing of some prepositions such as in abroad, d) misusing of some verbs in English because of the negative effect of Turkish such as ...won the university entrance exam, e) selection of wrong tense in storytelling.

\section{Assessment of the study}

Due to the limitation of subjects and time, the subject students' errors should not be generalized for all the EFL students in Turkey. Thus, further research is needed in order to increase our knowledge of interference and developmental errors made by Turkish EFL students.

\section{Implications for future research}

Since some of the students in this study made \%14.6 interference errors, it is recommended to do further research on their errors in writing. Also, the causes of those errors can be explained to the learners before teaching. To do so a further study is needed.

\section{REFERENCES}

Brown, D. H. (1980). Principles of language learning \& teaching. (4th ed.). New York: Longman, 148.

Corder, S. P. (1967). The significance of learner's errors. International Review of Applied Linguistics. 5, 161-170.

Dulay, H., Burt, M., \& Krashen, S. (1982). Language Two. New York: Oxford University Press. 
Dulay, H. C., \& M. K. Burt (1974). Errors and strategies in child second language acquisition. TESOL Quarterly, 8, 129-136.

Edge, J. (1989). Mistakes and correction. London: Longman Group UK Limited.

Elk1lıç, G. (2012) Mother Tongue Traces of Turkish University Students on Composition Papers Written in English, Procedia - Social and Behavioral Sciences 47:656664 - December 2012, DOI: 10.1016/j.sbspro.2012.06.713

Finocchiaro, M. (1974). English as a second language form theory to practice. New York: Regents Publishing Company.

Gass, S. M. \& Selinker, L. (2008). Second Language Acquisition: An Introductory Course. New York, NY: Routledge.

Grauberg, W. (1971). An error analysis in German of first-year university students. in Perren and Trim (Eds.) Applications of linguistics. Papers from the Second International Congress of Applied Linguistics. Cambridge: Cambridge University Press.

Janicki, K. (1985). The foreigner's language: A socio linguistic perspectives. Exeter: A. Wheaton \& Co. ltd.

Klassen, J. (1991). Using student errors for teaching. English Teaching Forum, 29, 10-16.

Lado, Robert (1957). Linguistics Across Cultures, Michigan: University of Michigan Press.

Littlewood, W. T. (1984). Foreign and second language learning. Language-acquisition research and its applications for the classroom. Cambridge: Cambridge University Press.

Lott, D. (1983). Analyzing and counteracting interference errors. ELT Journal, 37, 256-261.

Mukattash, L. (1986). Persistence of Fossilization, IRAL, vol. 24, no 3.

Norrish, J. (1983). Language learners and their errors. London: Macmillan Press.

Richards, J. C., \& Rodgers, T. S. (1986). Approaches and methods in language teaching: A description and analysis. Cambridge: Cambridge University Press.

Richards, J. C. (1974). Error Analysis Perspectives on Second Language Acquisition. Singapore: Longman Group Limited.

Robinnet, B. W., \& Schachter, J. (1983). Second language learning. Michigan: The University of Michigan Press.

Sharma, S. K. (1981). Error analysis: Why and how? English Teaching Forum, 19, 21-25.

Unal, S. (1989). An analysis of the errors in the compositions of the Turkish university students learning English. Unpublished master's thesis, Middle East Technical University, Ankara.

Walz, J. C. (1982). Error correction techniques for the foreign language classroom. Language in education: Theory and practice. (Report No. FL 012 967). (Eric Document Reproduction Service No. ED 217 704)

Wardhaugh, Ronald (1970). The Contrastive Analysis Hypothesis, TESOL Quarterly. vol. 4 no 2. pp. 123-130.

\section{$\underline{\text { AUTHORS' BIO }}$}

Şahin GÖK is an Assistant Professor at the Department of Foreign Language, Istanbul Gelisim University. 